\title{
DESIGN FOR RESILIENT HUMAN-SYSTEM INTERACTION IN AUTONOMY: THE CASE OF A SHORE CONTROL CENTRE FOR UNMANNED SHIPS
}

\author{
Veitch, Erik Aleksander; \\ Kaland, Thomas; \\ Alsos, Ole Andreas \\ Norwegian University of Science and Technology
}

\begin{abstract}
Artificial intelligence is transforming how we interact with vehicles. We examine the case of Maritime Autonomous Surface Ships (MASS), which are emerging as a safer and more effective solution for maritime transportation. Despite the focus on autonomy, humans are predicted to have a central role in MASS operations from a Shore Control Centre (SCC). Here, operators will provide back-up control in the event of system failure. There are signification design challenges with such a system. The most critical is human-system interaction in autonomy (H-SIA). We consider humans as the source of resilience in the system for adapting to unexpected events and managing safety. We ask, can HumanCentred Design (HCD) be used to create resilient interactions between MASS and SCC? Work has been done in resilience engineering for complex systems but has not been extended to H-SIA in transportation. "Resilient interaction design" is relevant as we progress from design to operational phase. We adopted the ISO 9421-210 guideline to structure our HCD approach. The result is an SCC designed for 1 Autonomy Operator (AO). The contribution is a demonstration of how resilient interaction design may lead to safer and more effective H-SIA in transportation.
\end{abstract}

Keywords: Shore Control Centre, User centred design, Design methods, Systems Engineering (SE), Autonomous Systems

Contact:

Veitch, Erik Aleksander

NTNU

Department of Design

Norway

erik.a.veitch@ntnu.no

Cite this article: Veitch, E. A., Kaland, T., Alsos, O. A. (2021) 'Design for Resilient Human-System Interaction in Autonomy: The Case of a Shore Control Centre for Unmanned Ships', in Proceedings of the International Conference on Engineering Design (ICED21), Gothenburg, Sweden, 16-20 August 2021. DOI:10.1017/pds.2021.102 


\section{INTRODUCTION}

\subsection{Designing for resilience in autonomous systems: the case of unmanned ships}

Artificial Intelligence (AI) is changing how we interact with vehicles. In this paper, we look at the case of unmanned ships with autonomous navigation capability. Unmanned ships are termed Maritime Autonomous Surface Ships (MASS) by the International Maritime Organization (IMO), the United Nations agency regulating international maritime safety. We use the terms 'MASS' and 'unmanned ship' interchangeably in this paper.

Historically, researchers have taken a measured approach when assessing the potential for MASS to improve safety by reducing human-related accidents, pointing out that new failures modes related to interaction with the autonomy system will present themselves (Ahvenjärvi, 2016; Chang et al., 2020; Ramos et al., 2020a). Researchers largely concede that full autonomy, whereby the AI is so complete as to remove the need for humans completely, is not a realistic operating model for which to currently plan. It emerges that humans remain central to safe operation of MASS, despite the promise of more machine autonomy. This 'irony of automation' has been observed before in automation applications (Bainbridge, 1982; Parasuraman and Wickens, 2008). We observe a similar 'irony of automation' emerging in the wake of unmanned ships, manifested in the Shore Control Centre (SCC) concept. In current operating models of MASS, the SCC serves predominantly a back-up role: when the AI fails to solve a navigation problem, the autonomy shifts to a fail-safe state until operators at the SCC intervene to resolve the problem and, once resolved, return the system to an autonomous state.

Risk researchers have predicted that the interaction between humans and the autonomy system will be the root cause for the most consequential propagation of accidents (Chang et al., 2020; Ramos et al., 2020b). The term Human-System Interaction with Autonomy (H-SIA) was introduced as way to assess the safety of this interaction (Ramos et al., 2020a). Despite the focus on risk, human interaction elements also represent an opportunity for designers to strengthen the system. Should operators at the SCC be better equipped to flexibly react and adapt to problems not only when they arise, but also before they arise, then the overall effect would be a safer and more effective system. The premise of adaptive control of safety while balancing productivity is the aim of resilience engineering (Hale and Heijer, 2006). Yet despite significant efforts in resilience engineering towards safer complex systems design and the innovations in modelling H-SIA risk, no research to date has sought to apply a HumanCentred Design (HCD) process with the aim of improving interaction resilience between SCC and MASS. This paper aims to fill that gap. The research question we ask is: can we use HCD to design for resilient interactions between MASS and SCC?

In Section 2, we describe the HCD method that we used to design a SCC. Section 3 presents findings and our SCC design. Section 4 discusses implications of this work, including for broader applications. Section 5 presents a conclusion and suggestions for future work in resilient interaction design for human-AI interaction in autonomous transportation.

\subsection{Scope}

In this paper, we consider SCC design applications that encompass four MASS types: urban, inland, coastal, and ocean-going (Figure 1). These are also defined in Table 1 along with some relevant reference projects.

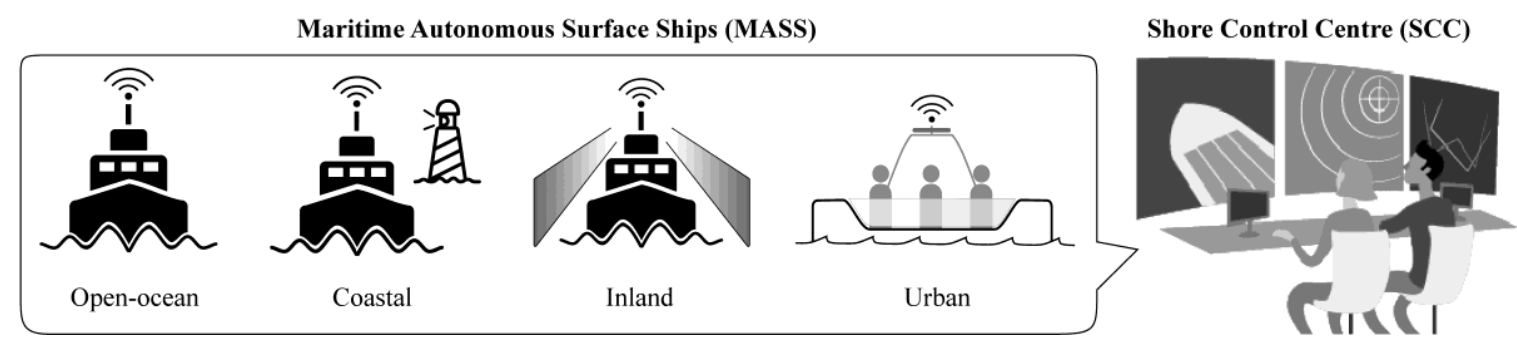

Figure 1. Autonomous maritime system comprising of MASS and SCC 
Table 1. Scope of MASS types in this paper

\begin{tabular}{|l|l|l|}
\hline Type & Description & Reference projects \\
\hline Urban & $\begin{array}{l}\text { Small vessels (length approx. 5-10 m) transporting } \\
\text { passengers or goods in urban canals or waterways }\end{array}$ & $\begin{array}{l}\text { Autoferry (Reddy et al., 2019); } \\
\text { RoBoat (MiT, 2020) }\end{array}$ \\
\hline Inland & Inland cargo vessels for European inland waterways & $\begin{array}{l}\text { H2H Project (Peeters et al., } \\
\text { 2020) }\end{array}$ \\
\hline Coastal & $\begin{array}{l}\text { Short-sea shipping routes in trafficked channels with } \\
\text { aids to navigation present along the shore, Vessel } \\
\text { Traffic Services (VTS) communication, and } \\
\text { demanding navigation }\end{array}$ & $\begin{array}{l}\text { Land-Based Operation of } \\
\text { Autonomous Ships (LOAS); } \\
\text { SFI AutoShip (NTNU, 2021a) }\end{array}$ \\
\hline Ocean & $\begin{array}{l}\text { Open-ocean transportation with non-demanding } \\
\text { navigation }\end{array}$ & $\begin{array}{l}\text { MUNIN (Burmeister et al., } \\
\text { 2014) }\end{array}$ \\
\hline
\end{tabular}

\subsection{Levels of autonomy}

Levels of Autonomy (LoA) refers to how autonomous a system is on a spectrum from full manual control to full automatic control. For the Autonomous Maritime System (AMS) case, LoA has been shown to be an effective way to classify SCC-MASS interactions (Dybvik et al., 2020). There are many taxonomies for LoA and one comprehensive review finds that its definition is context specific (Vagia et al., 2016). For this study, we use the taxonomy in Table 2 proposed by NFAS (Rødseth, 2017) and assume the AMS is in "Constrained Autonomous" mode (Level 7).

Table 2. LOA for MASS from Rødseth (2017)

\begin{tabular}{|l|l|l|}
\hline LoA & Label & Definition \\
\hline 1 & Direct control & Direct control of ship from bridge crew, no decision support. \\
\hline 2 & Decision support & Decision support and advice to crew on bridge. Crew decides. \\
\hline 3 & Automatic bridge & Automated operation, under continuous supervision by crew. \\
\hline 4 & Periodically unmanned & Continuously supervised by shore. Muster crew if necessary. \\
\hline 5 & Remote control & Unmanned with monitoring and direct control from shore. \\
\hline 6 & Automatic & Unmanned under automatic control, monitored from shore. \\
\hline 7 & Constrained autonomous & Unmanned, partly autonomous, continuous shore supervision. \\
\hline 8 & Fully autonomous & Unmanned and without supervision. \\
\hline
\end{tabular}

\subsection{Shore control lab}

The Shore Control Lab (SCL) is an SCC owned and operated by the Norwegian University of Science and Technology (NTNU) with the mission of advancing AMS research (NTNU, 2021b). Its design is the main result of this paper. In our initial scoping of similar infrastructures, we found only a handful of SCCs in existence today. Of those that do exist, none have a proven operational concept, instead ranging from early to advanced prototypes. The earliest prototypes were limited by conventional ship bridge paradigms (MacKinnon et al., 2015). Recently, a new paradigm is emerging for SCC-based navigation (Veitch et al., 2020). For example, an advanced functional prototype of an SCC for inland MASS has been built (Peeters et al., 2020) and a ship management company specializing in coastal MASS has led to innovative SCC designs (Massterly, 2021). Both projects have demonstrated efforts to base designs on specific SCC requirements rather than fitting the model of a conventional ship's bridge to the shore-based control centre mould.

As SCC prototypes advance, they are expected to unlock operational capabilities of MASS. However, before MASS can operate in marine traffic with conventional ships, there is a need for systematic and repeatable testing of human-AI interaction scenarios in the SCC to ensure safer and effective future maritime operations. The SCL is therefore a platform for addressing this research need. Its implications also have relevance to broader human-AI interaction issues in other transportation applications.

\section{METHOD}

We applied HCD principles to design the SCC. To do this in a way that was rigorous, tracing design decisions transparently to observations, we adopted the ISO design guideline 9241: Ergonomics of human-system interaction, Part 210: Human-centred design for interactive systems standard (ISO, 
2019). We refer to this as ISO 9241-210 for short. This method is depicted in Figure 2. It is a relevant design guideline because it is meant for interactive systems like that typified by the SCC; although, design for autonomous interactive systems is not explicitly its focus.

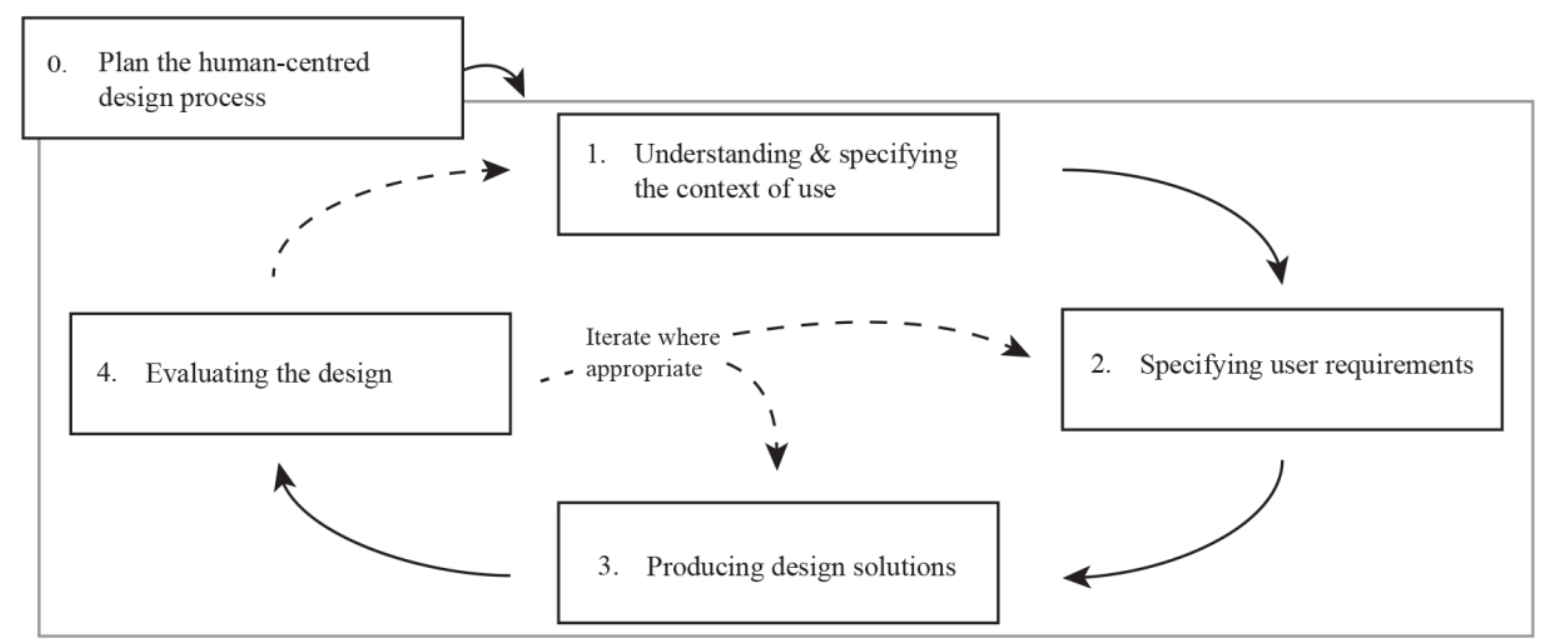

Figure 2. Human-centred design process adapted from ISO (2019)

\subsection{Design activities}

We used various design activities to collect information for Stages 1-4 of the HCD process in Figure 2. These design activities are depicted in Figure 3 along with their corresponding design stages. Details about each design activity are found in Sections 3.1 to 3.3.

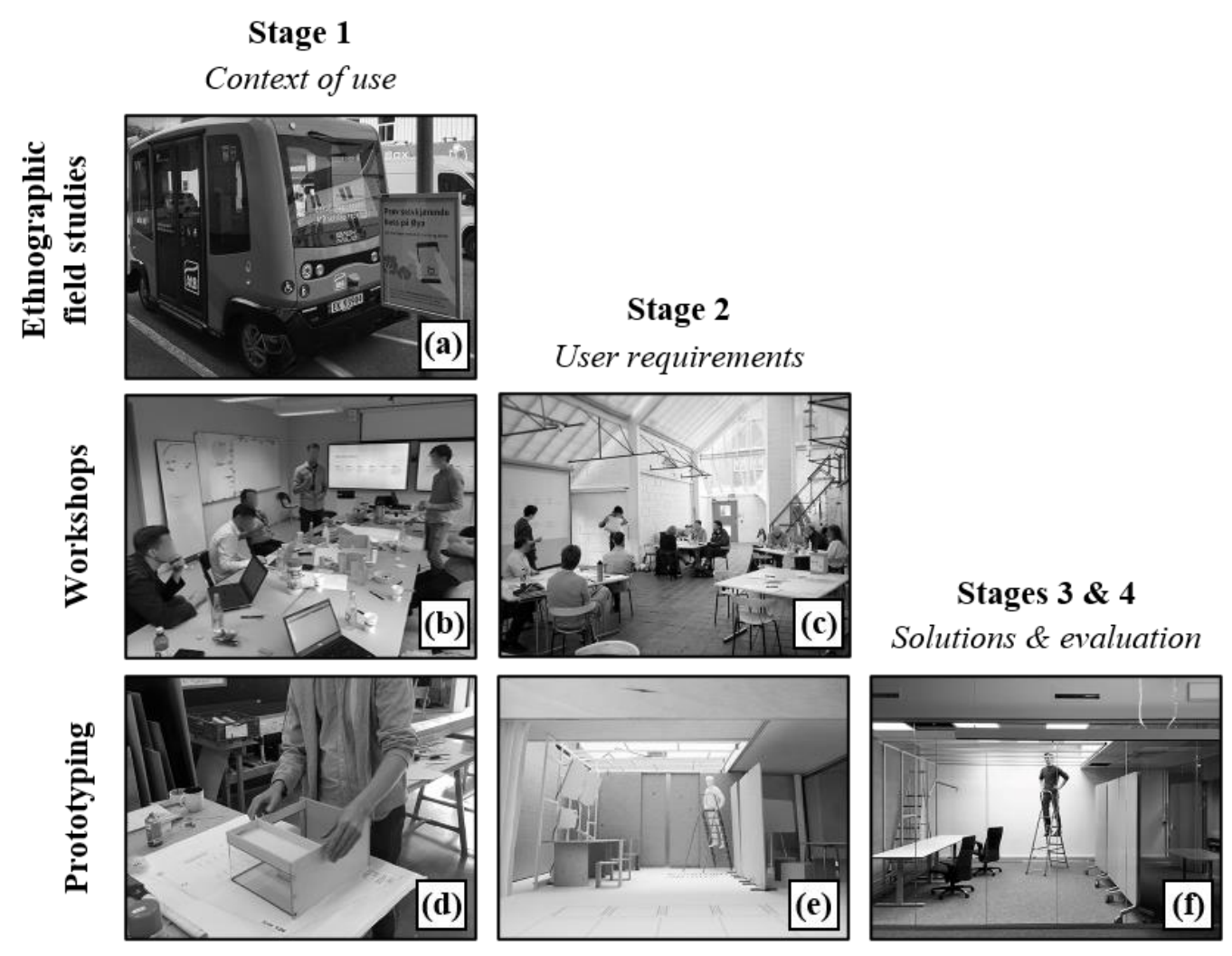

Figure 3. Design activities corresponding to stages 1-4 of the ISO 9241-210 HCD guideline.

(a) Autonomous bus case study (b) Stakeholder Workshop (c) Co-Creation workshop (d) Basic prototyping (e) Detailed prototyping (f) Full-scale prototyping 


\section{FINDINGS}

In this section we present a human-centred SCC design based on results from applying the ISO 9241210 guideline. It is divided into three subsections (and corresponds to the three columns in Figure 3):

1. Understanding and specifying the context-of-use: This phase involved information gathering and analysis with the purpose of describing the future context-of-use of SCCs. Context-of-use is broken down into four distinct elements, which are defined in Table 3. The corresponding design activities used to inform these four context-of-use elements are further listed in Table 4.

2. Specifying user requirements: Core user needs are listed in Figure 4 in terms of technical, physical, organizational, and cultural aspects and provide the basic functional requirements for the SCC.

3. Producing and evaluating design solutions: Concrete design solutions in form of physical prototypes were used to generate user-centred evaluation and design refinements. We present the full-scale SCC design (the SCL), in Figure 5.

\subsection{Understanding and specifying the context of use}

This was the first stage of the HCD design process (Figure 2). Our methods of data collection in this stage involved a workshop and two design ethnographic case studies. Descriptions of what these activities involved are listed in Table 4. There are two additional aspects to note about these design activities. The first is that participants in the Stakeholder Workshop (Figure 3b) were experienced university faculty members representing a variety of backgrounds, including engineering cybernetics, innovation management, interaction design, electronic systems, lab management, and sensor fusion. The second involves the formal definition of "design ethnography," which we adopt from Hanington and Martin (2012, pp. 60) as a method that "approximates the immersion methods of traditional ethnography, to... understand the user's world for design empathy and insight."

Table 3. Elements of context-of-use description (adopted from ISO, 2019)

\begin{tabular}{|l|l|l|}
\hline $\begin{array}{l}\text { Context-of-use } \\
\text { element }\end{array}$ & Tag & Definition \\
\hline $\begin{array}{l}\text { Users and } \\
\text { stakeholder groups }\end{array}$ & US & $\begin{array}{l}\text { Groups representing a relationship with futures SCCs that can be } \\
\text { described in terms of key goals and constraints. }\end{array}$ \\
\hline $\begin{array}{l}\text { Characteristics of } \\
\text { the users }\end{array}$ & C & $\begin{array}{l}\text { Relevant characteristics of the users including knowledge, skill, } \\
\text { experience, education, training, preferences, and capabilities. }\end{array}$ \\
\hline $\begin{array}{l}\text { Goals and tasks of } \\
\text { the users }\end{array}$ & GT & $\begin{array}{l}\text { Overall goals of the system as well as of users and the characteristics } \\
\text { of the tasks that can influence usability and accessibility. }\end{array}$ \\
\hline $\begin{array}{l}\text { Environment of the } \\
\text { system }\end{array}$ & E & $\begin{array}{l}\text { Technical environment (e.g. hardware, software, materials), physical } \\
\text { environment (e.g. lighting, spatial layout, furniture), and relevant } \\
\text { aspects of organizational structure and culture. }\end{array}$ \\
\hline
\end{tabular}

Table 4. Data collection methods informing relevant context-of-use elements

\begin{tabular}{|l|l|l|}
\hline Design method & Case study & Tag (Table 3) \\
\hline $\begin{array}{l}\text { Stakeholder } \\
\text { Workshop }\end{array}$ & $\begin{array}{l}\text { Structured workshop to identify stakeholders and their core } \\
\text { needs. Participants were six experienced university faculty } \\
\text { members from various disciplines. It was led by the authors. }\end{array}$ & US, C, GT \\
\hline $\begin{array}{l}\text { Ethnographic } \\
\text { case study 1 }\end{array}$ & $\begin{array}{l}\text { Contextual inquiry and interviews of remote air-traffic } \\
\text { controllers at Avinor Remote Towers } 1 \text { at Bodø Airport }\end{array}$ & C, GT, E \\
\hline $\begin{array}{l}\text { Ethnographic } \\
\text { case study 2 }\end{array}$ & $\begin{array}{l}\text { Contextual inquiry of "safety host" during normal operations } \\
\text { and manual takeover of public autonomous city bus }\end{array}$ & C, GT, E \\
\hline $\begin{array}{l}{ }^{1} \text { For more information, refer to Avinor (2021) } \\
{ }^{2} \text { For more information, refer to Vy (2020) }\end{array}$ \\
\hline
\end{tabular}

The results of the data collection activities in this phase are presented in the context-of-use description below. The results were integrated into a basic prototype of the SCC (Figure 3d) which was used to interactively discuss physical aspects of context-of-use like space usage and basic infrastructure (see Section 3.3 for more information about prototyping). 


\subsubsection{Context of use description}

Who are the SCC stakeholders? We distinguished between two main stakeholder groups: developers of AMS mobilizing for MASS operational phases and the end users of the SCC operating the controls first-hand. The latter group was representative of the operators who would work at the SCC. We called these primary SCC users the "Autonomy Operators" (AOs) to illustrate their main role: as a bridge between autonomous navigation tasks handled by AI and the human navigation responsibilities stemming from oversight, back-up intervention, and safety management. After the Stakeholder Workshop, we arranged a second workshop (the "Co-Creation Workshop") with invited participants representing these two groups' interests. Although the AOs did not yet exist, the relevant backgrounds of the workshop participants allowed us to infer information about them (see Section 3.3).

What are the characteristics of SCC users? The AOs where characterized as control room operators with skills in marine navigation. Conventional Bridge Resource Management (BRM) weighed heavily on how these users were characterized, with terms like "Captain" and "Master" being used to label their roles within a team hierarchy. Considering the novelty of AMSs, we avoided applying terminology used in conventional BRM to describe AO roles and tasks and instead characterized them broadly: as operators with competence in interacting with a dynamic LoA system and in decisionmaking related to intervention under time pressure and elevated risk.

What are the goals and primary tasks of the users? We inferred goals and primary tasks of the AOs in terms of two operational categories: single- and multi-vessel operations. Single-vessel operation is the focus in the beginning phase of SCC development, where the primary task is safe operation of a single vessel. Tasks span planning (pre-operation stage), monitoring (operation stage), intervention (situation handling and emergencies), and assessment (post-operation stage). After single-vessel operation is verified within an acceptable risk level, the goal will be to operate multiple vessels. New primary tasks will involve fleet management (multiple vessels) and resource management (multiple AOs in a team hierarchy). Note that it is not in the scope of this paper to describe all tasks in full.

What are the characteristics of the system environment compared to similar applications? The ethnographic case studies (Table 4) led to a richer understanding of the environmental context-of-use in relation to similar applications. For example, the visit to the Avinor Remote Towers at Bodø International Airport let us observe operators turning on ambient sound to hear the in-situ airplane engines for a more immersive experience, which illustrated to us the importance of audio feedback in situation awareness when operating from a remote location.

\subsection{Specifying user requirements}

Here we specify functional requirements for the SCC in terms of core user requirements. The data came from the Stakeholder Workshop (Figure 3b) and the Co-Creation Workshop (Figure 3c). Results focussed on identifying users and their needs were distilled into core user requirements and presented in Figure 4. It is outside the scope of this paper to dissect the specific operator information needs. For detailed information on this topic, the reader is referred to Lunde-Hanssen et al. (2020).

\subsection{Producing and evaluating design solutions}

Here design solutions for the SCC are generated based on core user requirements (Section 3.2). Design solutions took the physical form of prototypes in various levels of detail and culminated in the fullscale SCC (Figure 5). During the design process, prototypes were used to generate user-based evaluation to drive further, more detailed, iterations. This paper refers to four distinct prototypes, three of which are built today (the third is still under construction). These are listed below:

1. Basic Prototype: assembled with Medium-Density Fibreboard (MDF), plywood, cardboard, clear plastic, and grey modelling foam with some plastic components made on a Prusa MkII 3D printer, constructed to 1:20 scaled and mounted on a printed floor plan. This prototype helped to interactively discuss high-level aspects like general arrangement, space and lighting, and power and data connectivity. (See Figure 3d.)

2. Detailed Prototype: assembled from Basic Prototype with added details. As discussions with users and experts became more detailed, so did the Detailed Prototype. (See Figure 3e).

3. Full-scale SCC (for virtual simulator): At the time of writing, the full-scale SCC, called the Shore Control Lab (SCL), is under construction. (See Figure 5.)

4. Full-scale SCC (for real MASS): Evaluation of Prototype 3 will feed into this design. 
In the Co-Creation Workshop (Figure 3c), the basic prototype was interactively presented to thirteen participants representing stakeholder and expert groups to generate detailed user-oriented feedback. Participants came from a variety of backgrounds, including control room design for space applications, AI for autonomous cars, engineering design, marine navigation, and human factors. Results from this workshop fed into the detailed prototype and filtered into the full-scale SCC. The full-scale SCC, currently equipped for virtual simulation, is depicted in Figure 5 along with component descriptions.

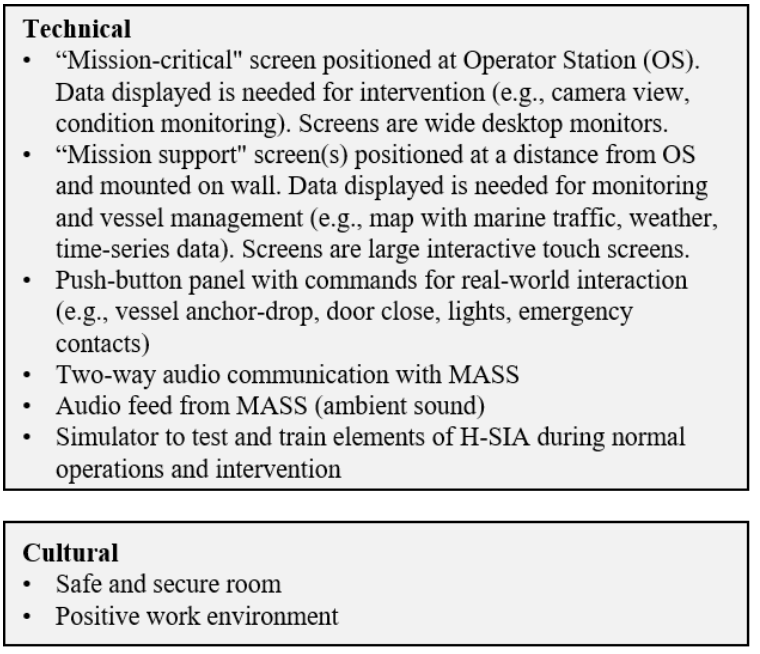

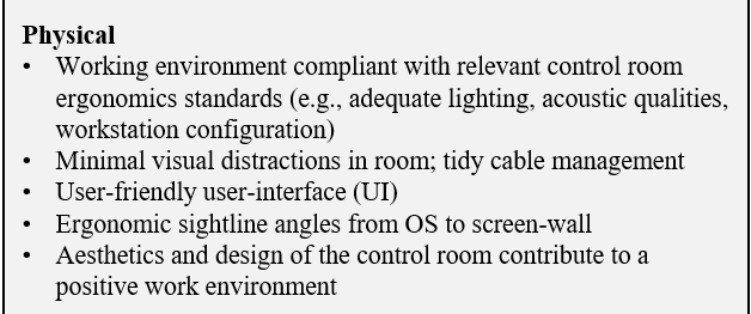

\section{Organizational}

- Tasks clearly defined within a hierarchy

- Operational and safety management procedures clearly defined

- Hazards identified and risks assessed

- Training for skills and decision-making competence, especially for intervention and other safety-critical scenarios

- Procedures and safety monitoring frameworks tested and verified using simulated scenarios

Figure 4. Core user requirements across four dimensions

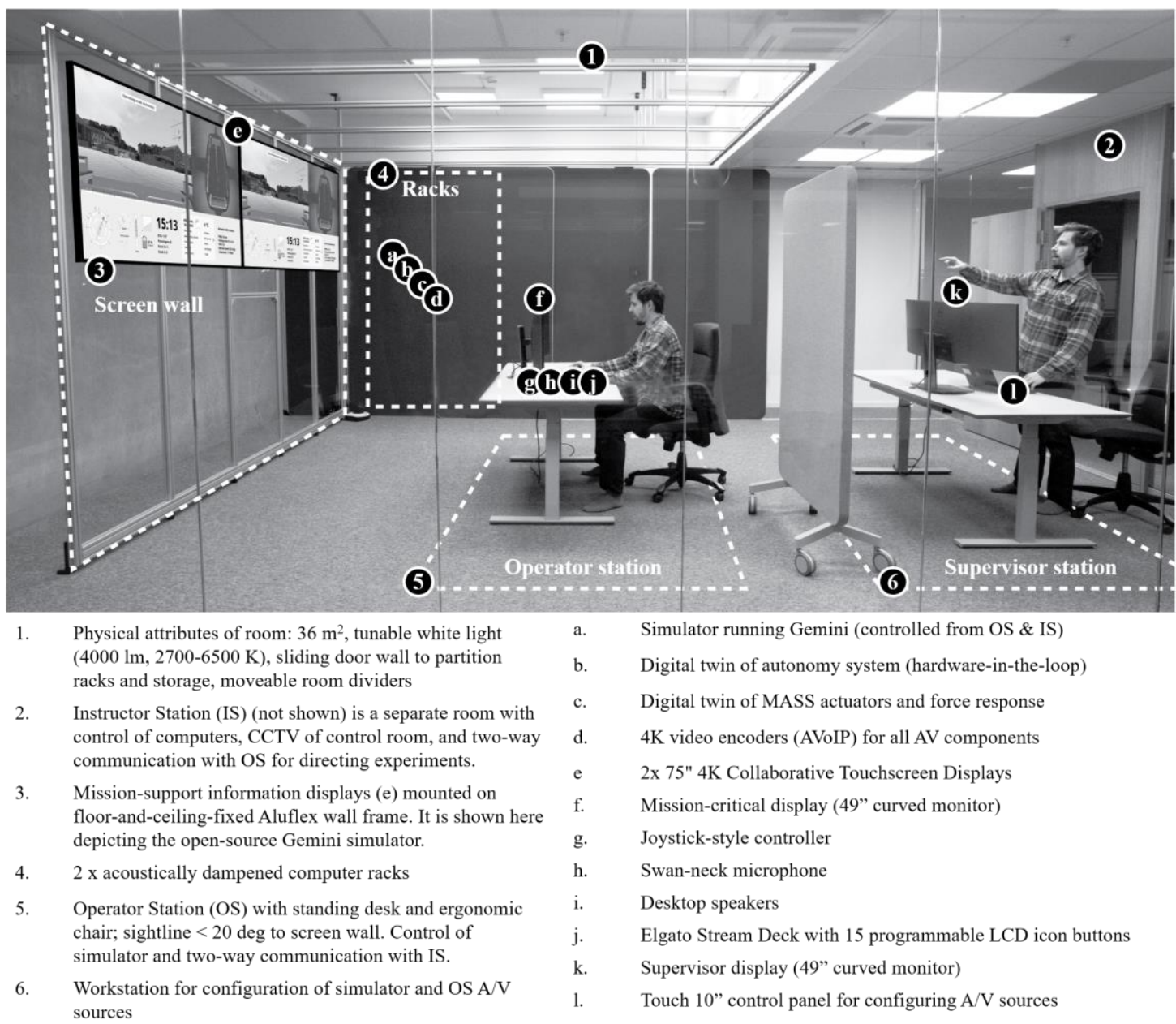

Figure 5. SCC physical attributes, system architecture \& core technical components 


\section{Discussion}

In this section we discuss the relevance of the results in terms of future work and application to other autonomous transportation systems.

\section{1 'Resilient interaction design' and applications to other fields}

We have shown how HCD methods helped to uncover needs of AOs in the SCC and led to informed design of interaction solutions for the AMS. The term 'resilient interaction design' (resilient IxD) is now introduced to describe contributions of designers in the face of emerging human-AI interaction design challenges in complex systems like those present in transportation applications. The work presented in this paper can be considered as a contribution to resilient IxD for AMSs.

One of the keys to resilient IxD lies in multi-disciplinary collaboration among specialist groups working on the issues specific to the MASS and to the SCC. However, as researchers in safety engineering have discovered, compartmentalizing aspects of complex operations often lies at the root of accidents (Leveson, 2016). Resilient IxD should therefore work towards closing the gap between the autonomy system and the human interacting with it, thus taking steps towards safer operations in a system perspective

The work presented also has relevance to applications outside of maritime operations. There is a general trend for autonomous transportation systems that rely on human intervention for safety. This human intervention is often done remotely from a coordinate centre that can handle multiple vehicles simultaneously. As we have seen, human-AI interactions are vulnerable to error propagation if poorly implemented. Recent examples where poorly implemented AI-interaction design has contributed to loss of vehicle control and fatal accidents include the Boeing 737 MAX accidents (Nicas et al., 2019) and Tesla 'Autopilot' crashes (U.S National Transportation Safety Board, 2017). Takeover instances in autonomous cars are exposed to the same underlying interaction vulnerabilities as in the SC case; namely, cognitive information gathering and processing under time pressure and high risk.

\subsection{Virtual simulator}

It emerged during the design process that the need for training, testing, verification, and assurance were all closely linked to the ability to run controlled and repeatable scenarios: something that is only practical in a simulator. Therefore, one of the main aims of the SCL was to provide integrated virtual simulation of the AMS. This is not trivial; there are many full-mission bridge simulators, but no analogues to the SCC. Future work at the SCL will aim to fill that gap. The ability to simulate AMS operations may also contribute to verification of frameworks for monitoring operational safety indicators, such as that proposed by Thieme and Utne (2017). The literature also points to a lack of empirical data to inform risk assessment models needed to quantify probabilistic error models related to interaction between MASS and SCC (Thieme et al., 2018; Wróbel et al., 2018). Simulation in the SCC can generate empirical data in virtual scenarios to help fill this gap.

We checked the literature for autonomous vehicle simulators and found promising development in the car industry, such as that exemplified by the open platform CARLA (Dosovitskiy et al., 2017). A similar open source technology platform is being development for MASS applications, called Gemini (Vasstein et al., 2020). The SCL will use the Gemini platform for future test campaigns. Future testing will incorporate the needs of AI testing and verification with human-AI interaction needs reflecting the resilient IXD framework.

\subsection{Strengths and limitations of the method}

The biggest advantage of adopting an HCD approach was that it led to specification of the SCC based on user requirements, instead of abstract requirements. We have drawn clear links between user requirements and design specifications in this paper. However, there are some important limitations in the method. The most obvious was that the core users, which we termed Autonomy Operators (AOs), do not yet exist in fully operational SCCs. The role is novel, and thus we had to infer needs of AOs from various sources, including from similar applications (remote air-traffic controllers and autonomous bus safety host in Section 3.1) and from domain experts in space control rooms, engineering design, car automation, and other fields that participated in our Co-Creation Workshop (Sections 3.2 and 3.3). In the Co-Creation Workshop, there was one experienced marine navigator with a certificate for bulk carriers who joined remotely. More information from seafarers would have 
been helpful because seafarers represent the most similar occupation to that of the AO in the SCC and therefore the most likely to become actual AOs. A cross-check in the literature suggests the same but points to necessary amendments of training conventions to make this possible (Katsivela, 2020; Kim and Mallam, 2020). Future work should include more user-testing on seafarers, set up specifically to gauge feedback on experience and to measure performance in pre-defined tasks. Virtual simulation may provide a useful tool for this purpose.

\section{CONCLUSION}

We have designed an SCC for MASS in constrained autonomous mode using an HCD method. This SCC is called the 'Shore Control Lab' and will be used for research. The contribution is a novel approach to designing more resilience into the AMS by addressing safety-critical interactions between humans and AI using HCD principles. We systematically and transparently designed for AO needs, framing AOs as a central source of operational resilience in aspects such as decision-making and safety monitoring. The implications are safer and more effective operations of MASS. Other autonomous vehicles that depend on human-AI interaction for operational management and control can benefit from this approach, such as vehicle traffic with remote operator assistance. In this paper we examined the case of a single operator-single vehicle control station, although the solution is scalable for multiple vehicles managed from a single coordination centre with a team of operators. We introduce the term 'resilient interaction design' to refer to research and development contributing to solutions for safer and more effective design of human-AI interaction aspects through application of HCD principles.

\section{ACKNOWLEDGMENTS}

We acknowledge (1) NTNU for funding the Shore Control Lab infrastructure, (2) the Norwegian Research Council for funding the project "Land-based Operation of Autonomous Ships" (Grant Number 296527), and (3) all the workshop participants and experts for valuable information and feedback.

\section{REFERENCES}

Ahvenjärvi, S. (2016), "The human element and autonomous ships", TransNav: International Journal on Marine Navigation and Safety of Sea Transportation, Vol. 10, No. 3, pp. 517-521. https://dx.doi.org/10.12716/1001.10.03.18.

Avinor (2021), Remote Towers: The technology of the future at Norwegian airports [online]. Avinor AS. Available at https://avinor.no/en/remote (accessed 3.23.21).

Bainbridge, L. (1982), "Ironies of Automation", IFAC Proceedings, Vol. 15, pp 129-135. https://dx.doi.org/10.1016/S1474-6670(17)62897-0

Burmeister, H.C., Bruhn, W., Rødseth, Ø.J., Porathe, Т. (2014), “Autonomous Unmanned Merchant Vessel and its Contribution towards the e-Navigation Implementation: The MUNIN Perspective", International Journal of e-Navigation and Maritime Economy, Vol. 1, pp. 1-13. DIO: 10.1016/j.enavi.2014.12.002

Chang, C.H., Kontovas, C., Yu, Q., Yang, Z. (2020), "Risk assessment of the operations of maritime autonomous surface ships”, Reliability Engineering \& System Safety, Vol. 207, pp. 111. https://dx.doi.org/10.1016/j.ress.2020.107324

Dosovitskiy, A., Ros, G., Codevilla, F., Lopez, A., Koltun, V. (2017), “CARLA: An open urban driving simulator", Proceedings of the 1st Annual Conference on Robot Learning, Proceedings of Machine Learning Research, Mountain View, CA, USA, pp. 1-16.

Dybvik, H., Veitch, E., Steinert, M. (2020), "Exploring challenges with designing and developing Shore Control Centres (SCC) for autonomous ships", Proceedings of the Design Society: Design Conference, Vol. 1, pp. 847-856. https://dx.doi.org/10.1017/dsd.2020.131

Hale, A., Heijer, T. (2006), "Defining resilience", In: Hollnagel, E., Woods, D.D., Levesen, N. (Ed.), Resilience engineering: Concepts and precepts, CRC Press, Boca Raton, FL, USA, pp. 35-40.

Hanington, B., Martin, B. (2012), Universal Methods of Design: 100 Ways to Research Complex Problems, Develop Innovative Ideas, and Design Effective Solutions. Rockport Publishers, Beverly, MA, USA.

IMO (2017), International Convention on Standards of Training, Certification and Watchkeeping for Seafarers (STCW) 1978, as amended in 1995/2010, International Maritime Organization, London.

ISO (2019), NS-EN ISO 9241-210:2019, Ergonomics of human-system interaction - Part 210: Human-centred design for interactive systems, European Committee for Standardization, Brussels, Belgium.

Katsivela, M. (2020), "Unmanned Vessels and Regulatory Concerns", Journal of International Maritime Law, Vol. 26, pp. 239252. 
Kim, T., Mallam, S. (2020), “A Delphi-AHP study on STCW leadership competence in the age of autonomous maritime operations", WMU Journal of Maritime Affairs, Vol. 19, pp. 163-181. https://dx.doi.org/10.1007/s13437-020-00203-1

Leveson, N.G. (2016), Engineering a Safer World: Systems Thinking Applied to Safety. The MIT Press, Cambridge, MA, USA.

Lunde-Hanssen, L.S., Braseth, A.O., Strand, S. (2020), Identification of information requirements in ROC operations room (No. IFE/E-2020/007), IFE, Halden, Norway.

MacKinnon, S., Man, Y., Baldauf, M. (2015). Final Report: Shore Control Centre. MUNIN Project, Gothenburg, Sweden.

Massterly (2021), Making autonomy a reality, [online]. Massterly AS. Available at https://www.massterly.com/news (accessed 3.21.21).

MiT (2020), Roboat Project. [online]. MIT. Available at: roboat.org (accessed 11.19.20).

Nicas, J., Kitroeff, N., Gelles, D., \& Glanz, J. (2019). Boeing Built Deadly Assumptions into 737 Max, Blind to a Late Design Change. [online]. The New York Times. Available at: https://www.nytimes.com/2019/06/01/business/boeing-737-max-crash.html (accessed 3.17.21).

NTNU (2020), Autoferry. [online]. NTNU. Available at: ntnu.edu/autoferry (accessed 10.1.20).

NTNU (2021a), SFI AutoShip. [online]. NTNU. Available at: ntnu.edu/sfi-autoship (accessed 3.21.21).

NTNU (2021b), NTNU Shore Control Lab. [online]. NTNU. Available at: https://www.ntnu.edu/shorecontrol (accessed 4.21.21)

Parasuraman, R., Wickens, C.D. (2008), "Humans: Still Vital After All These Years of Automation”, Human Factors, Vol. 50, pp. 511-520. https://dx.doi.org/10.1518/001872008X312198.

Peeters, G., Yayla, G., Catoor, T., Van Baelen, S., Afzal, M.R., Christofakis, C., Storms, S., Boonen, R., Slaets, P. (2020), "An Inland Shore Control Centre for Monitoring or Controlling Unmanned Inland Cargo Vessels", Journal of Marine Science and Engineering, Vol. 8, No. 10: 758. https://dx.doi.org/10.3390/jmse8100758

Ramos, M.A, Thieme, C.A., Utne, I.B., Mosleh, A. (2020a), "Human-system concurrent task analysis for maritime autonomous surface ship operation and safety", Reliability Engineering \& System Safety, Vol. 195. https://dx.doi.org/10.1016/j.ress.2019.106697

Ramos, M.A., Thieme, C.A., Utne, I.B., Mosleh, A. (2020b), “A generic approach to analysing failures in human-System interaction in autonomy," Safety Science, Vol. 129. https://dx.doi.org/10.1016/j.ssci.2020.104808

Reddy, N.P., Zadeh, M.K., Thieme, C.A., Skjetne, R., Sorensen, A.J., Aanondsen, S.A., Breivik, M., Eide, E. (2019), "Zero-Emission Autonomous Ferries for Urban Water Transport: Cheaper, Cleaner Alternative to Bridges and Manned Vessels", IEEE Electrification Magazine, Vol. 7, pp. 32-45.

Rødseth, Ø.J. (2017), Definitions for Autonomous Merchant Ships, NFAS, Trondheim, Norway.

Salmon, P.M., Walker, G.H., Stanton, N.A. (2016), "Pilot error versus sociotechnical systems failure: a distributed situation awareness analysis of Air France 447”, Vol. 17, pp. 64-79. https://dx.doi.org/10.1080/1463922X.2015.1106618

Thieme, C.A., Utne, I.B. (2017), "Safety performance monitoring of autonomous marine systems", Reliability Engineering \& System Safety, Vol. 159, pp. 264-275. https://dx.doi.org/10.1016/j.ress.2016.11.024

Thieme, C.A., Utne, I.B., Haugen, S. (2018), “Assessing ship risk model applicability to Marine Autonomous Surface Ships”, Ocean Engineering, Vol. 165, pp. 140-154. https://dx.doi.org/10.1016/j.oceaneng.2018.07.040

U.S. National Transportation Safety Board (2017). Collision Between a Car Operating With Automated Vehicle Control Systems and a Tractor-Semitrailer Truck Near Williston, Florida May 7, 2016, Accident Report HAR1702, National Transportation Safety Board, Washington, D.C., USA.

Vagia, M., Transeth, A.A., Fjerdingen, S.A. (2016), "A literature review on the levels of automation during the years. What are the different taxonomies that have been proposed?" Applied Ergonomics, Vol. 53, pp. 190-202. https://dx.doi.org/10.1016/j.apergo.2015.09.013

Vasstein, K., Brekke, E.F., Mester, R., Eide, E. (2020), “Autoferry Gemini: a real-time simulation platform for electromagnetic radiation sensors on autonomous ships", IOP Conference Series: Materials Science and Engineering, Vol. 929, 012032. https://dx.doi.org/10.1088/1757-899x/929/1/012032

Veitch, E., Hynnekleiv, A., Lützhöft, M. (2020), “The Operator's Stake in Shore Control Centre Design: A Stakeholder Analysis for Autonomous Ships", Proceedings of the Royal Institution of Naval Architects. Presented at the Human Factors, The Royal Institution of Naval Architects, London, UK. https://doi.org/10.3940/hf.20

Vy (2020), Try Europe's first self-driving reservation-only bus. [online] Vy. Available at: https://www.vy.no/en/news/europes-first-self-driving-bus (accessed 12.4.20).

Wróbel, K., Montewka, J., Kujala, P. (2018), "System-theoretic approach to safety of remotely-controlled merchant vessel,” Ocean Engineering, Vol. 152, pp. 334-345. https://dx.doi.org/10.1016/j.oceaneng.2018.01.020 